\title{
RISK OF MALIGNANCY INDEX IN PREOPERATIVE EVALUATION OF ADNEXAL MASSES
}

\author{
Augusti Mary Priyanka1, Shubhada Suhas Jajoo²
}

13rd Year Resident, Department of Obstetrics and Gynaecology, Dutta Meghe Institute of Medical Sciences, Sawangi, Wardha, Maharashtra, India.

2Professor, Department of Obstetrics and Gynaecology, Dutta Meghe Institute of Medical Sciences, Sawangi, Wardha, Maharashtra, India.

\begin{tabular}{l}
\hline ABSTRACT \\
BACKGROUND \\
Ovarian tumour usually presents as adnexal mass but often it is difficult to differentiate between benign and malignant tumour. \\
Several diagnostic modalities such as sonography and tumour markers have been evaluated in the past, but none have been \\
established as an ultimate diagnostic tool individually. The development of a mathematical formula using a logistic model, \\
incorporating menopausal status, the serum level of a glycoprotein called CA-125 and USG score has been described in the form of \\
different malignancy indices. The purpose of this study was to evaluate the various risks of malignancy indices (RMI 4 ) in the pre- \\
operative evaluation of adnexal masses, especially to differentiate between benign and malignant masses. Another objective of the \\
present study is statistical analysis of parameters like specificity, sensitivity, positive predictive value and negative predictive \\
value.
\end{tabular}

\section{MATERIALS AND METHODS}

The prospective observational study of patients with adnexal masses detected during ultrasonography, who were scheduled for surgical exploration of adnexal mass and histopathological diagnosis, were included in the study. Histopathological examination was taken as gold standard to calculate the accuracy of RMI. The sensitivity, specificity and positive predictive value and negative predictive value of all the four RMI were calculated and data analysed. A total of 100 patients were included in the study over a period of 2 years.

\section{RESULTS}

Sensitivity of RMI-4 was $91.2 \%$. Specificity of RMI was calculated to be $98.7 \%$. Positive and negative predictive values of RMI were $98.1 \%$, and $93.7 \%$, respectively with ROC of 0.95 . The best cut off value of RMI is 300 .

\section{CONCLUSION}

Risk of Malignancy Index is a good diagnostic tool to differentiate between benign and malignant adnexal masses.

\section{KEY WORDS}

RMI, Adnexal Mass, Ovarian Masses Cancer.

HOW TO CITE THIS ARTICLE: Priyanka AM, Jajoo SS. Risk of malignancy index in preoperative evaluation of adnexal masses. J. Evolution Med. Dent. Sci. 2018;7(50):5352-5357, DOI: 10.14260/jemds/2018/1185

\section{BACKGROUND}

Cancer has become a significant public health problem with over 8,00,000 new cases occurring every year and is the tenth cause of death in India. ${ }^{[1]}$ In India, incidence of ovarian cancer (OC) is $2.4 \%{ }^{[2]}$ Ovarian Cancer being contributing about $19.8 \%$ of total cases.[3] Seventy percent of cases are diagnosed at advanced stage with poor prognosis.[4],[5] The death mortality rate of ovarian cancer is $70 \%$ within 2 years and $90 \%$ within five years. ${ }^{[6]}$

Until now Researches invented various screening techniques for ovarian cancer but, due inadequate performance they have been ineffective. [7] The correct diagnosis of ovaries cancer is a challenging issue for the gynaecologist because of its bizarre and non-specific symptoms.[8] Ovarian cancer occurs as adnexal masses which gives rise to various malignant and benign conditions ${ }^{[6],[9]}$

'Financial or Other Competing Interest': None.

Submission 26-07-2018, Peer Review 22-11-2018,

Acceptance 29-11-2018, Published 10-12-2018.

Corresponding Author:

Dr. Augusti Mary Priyanka,

N-4/A, Aathrasia Chowk,

Laxmi Nagar, Nagpur-440022,

Maharashtra, India.

E-mail: draugusti16@gmail.com

DOI: $10.14260 /$ jemds/2018/1185

\section{(c) (i) $\$$}

The accurate diagnostic procedure for symptomatic adnexal mass is exploratory laparotomy or laparoscopy. Several women with ovarian malignancy undergo suboptimal primary operations at local hospitals leading to residual tumour. Primary cytoreductive operation is one of the most significant prognostic factor in ovarian tumours.[10],[11] Hence, the amount of residual tumour inevitably affects the prognosis and adjuvant treatment modalities. The correct preoperative screening and appropriate treatment in early stage of ovarian tumour is of great importance.

The most widely used method in developed countries for predicting malignant pelvic masses is the Risk of Malignancy Index (RMI). The RMI is a simple scoring system incorporating basic sonographic parameters, serum cancer antigen 125 (CA-125) levels, and menopausal status. Jacobs et al in 1990 invented this mathematical formula and termed it as RMI - 1 for early diagnosis and referral of selected patients to oncologic centers.[12] Tingulstad et al. (1996) modified RMI in the year 1996 and called it RMI - 2 which gave sensitive of $80 \%$ and specificity of $92 \%$. [13] In the year 1999 Tiugulstad et al further updated RMI -2 and termed it as RMI - 3. The changes done in all three RMI were different scoring of ultrasound score (U) and menopausal status (M). Finally Yamamoto et al created RMI 4 by addition of tumour size (S) to the RMI calculation.[14] Prospective and retrospective validation of the four versions of the RMI have been done 
where a cut-off value of 200 for RMI $1-3$ and 450 for RMI 4 showed the best discrimination between benign and malignant adnexal masses with sensitivity and specificity $51 \%-90 \%$ and $51 \%-97 \%$ respectively.[8],[15]

The advantage of RMI is that it is a simplified scoring system that can be applied in clinical practice without any expensive or complicated methods. For example, whole-body positron emission tomography, CT and MRI scan. The RMI can used as a triage tool in local hospitals for timely referral and optimal treatment of the patients with ovarian tumours. ${ }^{[8]}$ The purpose of this study was to evaluate the ability of the RMI to differentiate between malignant and benign pelvic masses in our population.

\section{Aim and Objectives}

- To analyse the scope of the Risk of Malignancy Index (RMI) - 4 to distinguish malignancy from benign adnexal masses.

- To ascertain the best cut off value of RMI for differentiating benign and malignant adnexal masses.

\section{Study Duration}

This prospective observational study was done for 2 years, between August 2016 and July 2018 at the department of Obstetrics and Gynaecology, AVBRH Sawangi Wardha after approval from institutional ethics committee.

\section{Inclusion Criteria}

Women with adnexal mass admitted for evaluation and treatment

\section{Exclusion Criteria}

Women already diagnosed with malignancy and received chemotherapy

\section{MATERIALS AND METHODS}

Detailed history, pelvic and physical examination, laboratory findings i.e. CA-125 levels of 132 cases were recorded. Ultrasound examination was done (Transvaginal and Abdominal).

\section{For each Case, Risk of Malignancy Formula applied-}

- $\quad$ Risk of Malignancy Index Formula - 4

- $\mathrm{RMI}=$ Ultrasound Score $(\mathrm{U}) \times$ Menopausal Status $(\mathrm{M}) \times$ CA-125 (IU $/ \mathrm{ml}) \times$ Tumour Size $(>7 \mathrm{~cm}$ )

- $\quad$ RMI of each patient was calculated by this formula.

\section{Menopausal Status (M)}

- Women with amenorrhea more than a year and more than 50 years old were considered as postmenopausal women and scored as $\mathrm{M}=4$.

- All other women were premenopausal and are scored as $\mathrm{M}=1$.

\section{Ultrasound Score (U)}

- USG Machine Aloka ARIETTA 70

- USG - CURVILINEAR PROBE 3-5 MHZ

- USG - TRANSVAGINAL PROBE 7.5-15 MHZ
Ultrasound Examination was done by the radiologist according to the following criteria (One point is given for each):

1. Multilocularity,

2. presence of solid areas,

3. presence of ascites,

4. bilaterally

5. Presence of intra-abdominal metastases.

- A zero or one point gives $\mathrm{U}=1$,

- Total of 2 or more points gives $U=4$,

\section{Serum CA-125 levels}

The numeric value of CA-125 level is entered in the formula.

\section{Tumour Size}

Single greatest diameter of the adnexal mass in ultrasonography

- $\quad<7 \mathrm{~cm}$ scored as $\mathrm{S}-1$

- $\quad>7 \mathrm{~cm}$ scored as $\mathrm{S}-2$

Diagnostic accuracy of RMI - 4 was done by comparing it with the gold standard Histopathologic results of all patients postoperatively.

\section{Statistical Analysis}

Statistical analysis was done by using descriptive and inferential statistics using chi square test, odd's ratio, sensitivity, specificity, PPV, NPV, Multivariate regression analysis, ROC analysis and software used in the analysis were SPSS 22.0 version and GraphPad Prism 6.0 version and $\mathrm{p}<0.05$ is considered as level of significance.

\section{RESULTS}

\begin{tabular}{|c|c|c|}
\hline Histopathological Diagnosis & Number $\mathbf{N}=132$ & N \% \\
\hline Benign & $(n=77)$ & $58.33 \%$ \\
\hline Serous Cystadenoma & 21 & 15.90 \\
\hline Dermoid Cyst & 17 & 12.87 \\
\hline Haemorrhagic Cyst & 13 & 9.84 \\
\hline Mucinous Cystadenoma & 8 & 6.06 \\
\hline Chocolate Cyst & 6 & 4.54 \\
\hline Follicular Cyst & 4 & 3.03 \\
\hline Luteal Cyst & 3 & 2.27 \\
\hline Fibroma & 2 & 1.51 \\
\hline $\begin{array}{l}\text { Chronic Granulomatous Lesion } \\
\text { Tuberculosis }\end{array}$ & 1 & 0.75 \\
\hline Paraovarian Cyst & 1 & 0.75 \\
\hline Stroma Ovarii & 1 & 0.75 \\
\hline Malignant & $(n=55)$ & $41.66 \%$ \\
\hline Serous Cystadenocarcinoma & 29 & 21.92 \\
\hline Mucinous Adenocarcinoma & 17 & 12.87 \\
\hline Dysgerminoma & 3 & 2.27 \\
\hline Endometrioid Cancer & 2 & 1.51 \\
\hline Transitional Cell Carcinoma & 2 & 1.51 \\
\hline Brenner's Tumour & 1 & 0.75 \\
\hline $\begin{array}{l}\text { Yolk Sac Tumour (Endo dermal } \\
\text { Sinus Tumour) }\end{array}$ & 1 & 0.75 \\
\hline \multicolumn{3}{|c|}{$\begin{array}{l}\text { Table 1. Distribution of Patients on Basis of } \\
\text { Histopathological Findings }\end{array}$} \\
\hline
\end{tabular}




\begin{tabular}{|c|c|c|c|}
\hline Variables & $\begin{array}{c}\text { Benign } \\
\text { N (\%) }\end{array}$ & $\begin{array}{c}\text { Malignant } \\
\text { N (\%) }\end{array}$ & P value \\
\hline Multilocularity & $64(83.11 \%)$ & $52(94.54 \%)$ & 0.047 \\
\hline Solid Area & $30(38.96 \%)$ & $52(94.54 \%)$ & 0.0001 \\
\hline Bilaterality & $6(7.79 \%)$ & $11(20 \%)$ & 0.039 \\
\hline Metastasis & $1(1.29 \%)$ & $37(67.27 \%)$ & 0.0001 \\
\hline Ascites & $3(3.89 \%)$ & $36(65.45 \%)$ & 0.0001 \\
\hline
\end{tabular}

Analysis of 132 patients with ultrasound features in respect of benign and malignant patients is shown in this table. The lesions were multilocular in $64(83.11 \%)$ benign cases and 52 (94.54\%) malignant group with a p value 0.047 . Findings as solid area are seen in 52 (94.54\%) of malignant cases and $30(38.96 \%)$ in benign group with a p value 0.0001 . The investigations further revealed that out of 132 patients of the study 17 cases had bilateral cyst and 115 had unilocular cyst with a $\mathrm{p}$ value 0.039 . Similarly rest of the features like metastasis $37(67.27 \%)$ and ascites $36(65.45 \%)$ were predominantly seen in malignant group with a significant $\mathrm{p}$ value (0.0001).

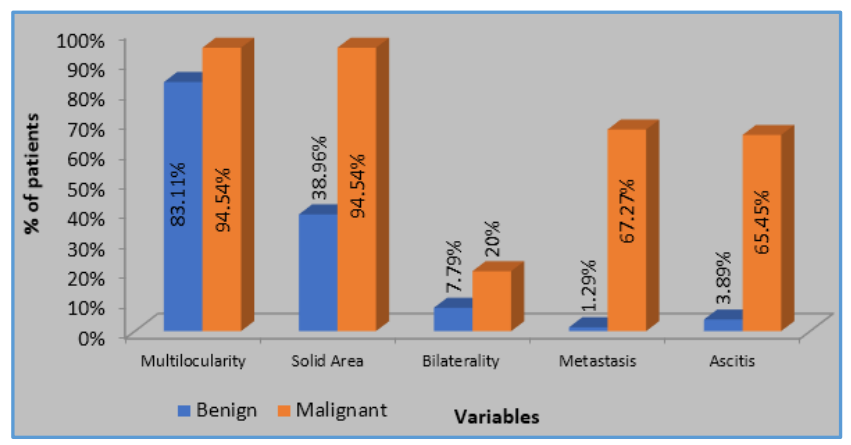

\begin{tabular}{|c|c|c|c|}
\hline Variables & Benign & Malignant & p value \\
\hline$<7 \mathrm{~cm}$ & $46(59.74 \%)$ & $10(18.18 \%)$ & \multirow{2}{*}{0.0001} \\
\cline { 1 - 3 }$\geq 7 \mathrm{~cm}$ & $31(40.26 \%)$ & $45(81.82 \%)$ & \\
\cline { 1 - 2 } Total & $\mathbf{7 7 ( 1 0 0 \% )}$ & $\mathbf{5 5}(\mathbf{1 0 0 \% )}$ & \\
\cline { 1 - 2 } Table 3. Distribution of Patients according to \\
Tumour Size in USG. \\
\hline
\end{tabular}

The tumour size was $>7 \mathrm{~cm}$ in $81.82 \%$ of malignant cases where as it showed a diminished percentage of $40.26 \%$ in benign cases. This table interprets that the tumour size $>7 \mathrm{~cm}$ has 1.5-fold increased risk for ovarian malignancy. This shows the association between the tumour size and malignancy were statistically significant at a $\mathrm{p}$ value of 0.0001 with Odds ratio $6.67(95 \% \mathrm{CI}=2.93-15.21)$

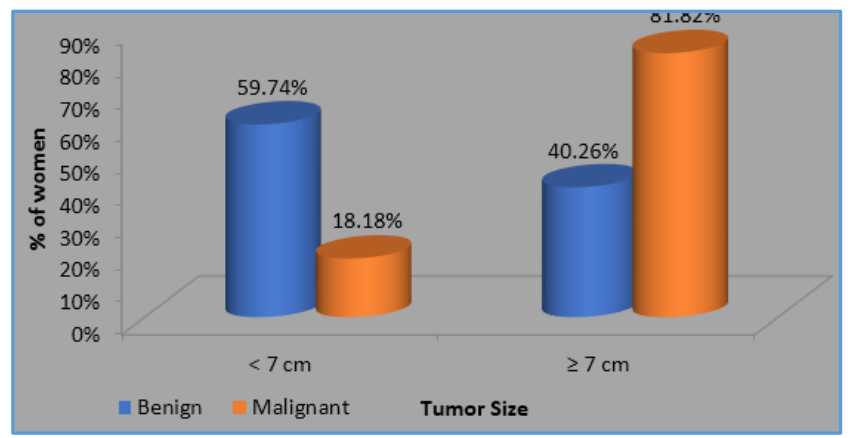

\begin{tabular}{|c|c|c|c|}
\hline Variables & Benign & Malignant & P Value \\
\hline$<35 \mathrm{u} / \mathrm{ml}$ & $67(87.01 \%)$ & $4(7.27 \%)$ & \multirow{2}{*}{$\mathrm{p}=0.0001$} \\
\cline { 1 - 3 }$\geq 35 \mathrm{u} / \mathrm{ml}$ & $10(12.99 \%)$ & $51(92.73 \%)$ & \\
\cline { 1 - 3 } Total & $\mathbf{7 7 ( 1 0 0 \% )}$ & $\mathbf{5 5}(\mathbf{1 0 0} \%)$ & \\
\cline { 1 - 3 } Mean \pm SD & $39.52 \pm 133.17$ & $1073.17 \pm 1403.67$ & \\
\cline { 1 - 1 } \multicolumn{2}{|c|}{ Table 4. Distribution of Patient according to CA 125 Level } \\
\hline
\end{tabular}

Odd's Ratio $=85.43(95 \%$ CI=25.33 -288.1$)$

The serum level of CA- 125 with a cut off value of $35 \mathrm{U} / \mathrm{ml}$ was analysed. It was found to be alarmingly high among women with malignancy (92.73\%) as compared to women with benign pelvic tumour (12.99\%) as reflected by 85.43 Odd's ratio $(95 \% \mathrm{CI}=25.33-288.1)$ with high significant $\mathrm{p}$ value.

\begin{tabular}{|c|c|c|c|}
\hline USG Score & Benign & Malignant & P value \\
\cline { 1 - 3 } Score -1 & $72(93.50 \%)$ & $1(1.81 \%)$ & \multirow{2}{*}{0.0001} \\
\cline { 1 - 3 } Score -4 & $5(6.49 \%)$ & $54(98.18 \%)$ & \\
\hline Total & $\mathbf{7 7 ( 1 0 0 \% )}$ & $\mathbf{5 5}(\%)$ & \\
\cline { 1 - 2 } Table 5. Distribution of Patients according to Ultrasound \\
Score \\
\hline
\end{tabular}

Odd's Ratio $=777.60(95 \% \mathrm{CI}=88.22-6854)$

Ultrasound score diagnosed $98.18 \%$ in malignant cases where as it was drastically down in benign cases only to the extent of $6.49 \%$. The accuracy of ultrasonography in the diagnosis of malignant ovarian tumours was found to be statistically significant with a p value of 0.0001 and very high Odd's ratio i.e 777.60 (95\% CI=88.22 - 6854).

\begin{tabular}{|c|c|c|c|}
\hline RMI - 4 & Benign & Malignant & P Value \\
\hline$\leq 450$ & $74(96.11 \%)$ & $3(5.45 \%)$ & \multirow{2}{*}{0.0001} \\
\cline { 1 - 2 } T450 & $3(3.89 \%)$ & $52(94.55 \%)$ & \\
\cline { 1 - 2 } Total & $\mathbf{7 7}(100 \%)$ & $55(100 \%)$ & \\
\cline { 1 - 2 } Table 6. Distribution of Patients according to Risk of \\
Malignancy Index- 4 Cut Off Value \\
\hline
\end{tabular}

Odd's Ratio $=427.6(95 \%$ CI $=82.98-2203)$, Mean \pm SD $=11497.02 \pm 30039.16(4.66-234016)$

Ascertaining the correlation with a cut off value of $>450$, out of 55 patients majority of cases were diagnosed malignant whereas only 3 cases were false positive and found to be benign, again with very significant $\mathrm{p}$ value and high Odd's ratio of 427.6 (95\% CI=82.98 - 2203).

\begin{tabular}{|c|c|c|c|c|c|}
\hline RMI - 4 & $\begin{array}{c}\text { Sensitivity } \\
\text { (\%) }\end{array}$ & $\begin{array}{c}\text { Specificity } \\
\text { (\%) }\end{array}$ & $\begin{array}{c}\text { PPV } \\
\text { (\%) }\end{array}$ & $\begin{array}{c}\text { NPV } \\
\text { (\%) }\end{array}$ & AUC \\
\hline 100 & 80.3 & 100 & 100 & 83.5 & 0.90 \\
\hline 200 & 86.9 & 100 & 100 & 89.9 & 0.93 \\
\hline 300 & 91.2 & 98.7 & 98.1 & 93.7 & 0.95 \\
\hline 400 & 90.9 & 96.1 & 94.3 & 93.7 & 0.94 \\
\hline 500 & 92.6 & 96.2 & 94.3 & 94.9 & 0.94 \\
\hline 1000 & 93.8 & 90.5 & 84.9 & 96.2 & 0.92 \\
\hline 5000 & 91.7 & 79.2 & 62.3 & 96.2 & 0.85 \\
\hline \multicolumn{7}{|r|}{ Table 7. Performance of RMI- 4 at Various Cut Off Levels } \\
\hline
\end{tabular}




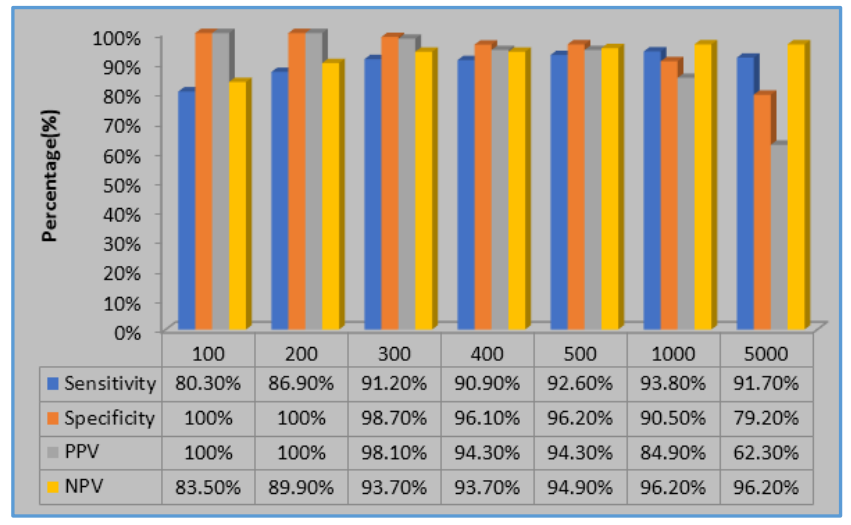

The sensitivity, specificity, positive predictive value and negative predictive value of RMI 4 at different cut off levels are mentioned in this table. As per RMI - 4 with the best cut off of 300 it showed highest sensitivity, specificity, positive predictive value and negative predictive value of $91.2 \%$, $98.7 \%, 98.1 \%, 93.7 \%$ respectively and the area under curve as 0.95 .

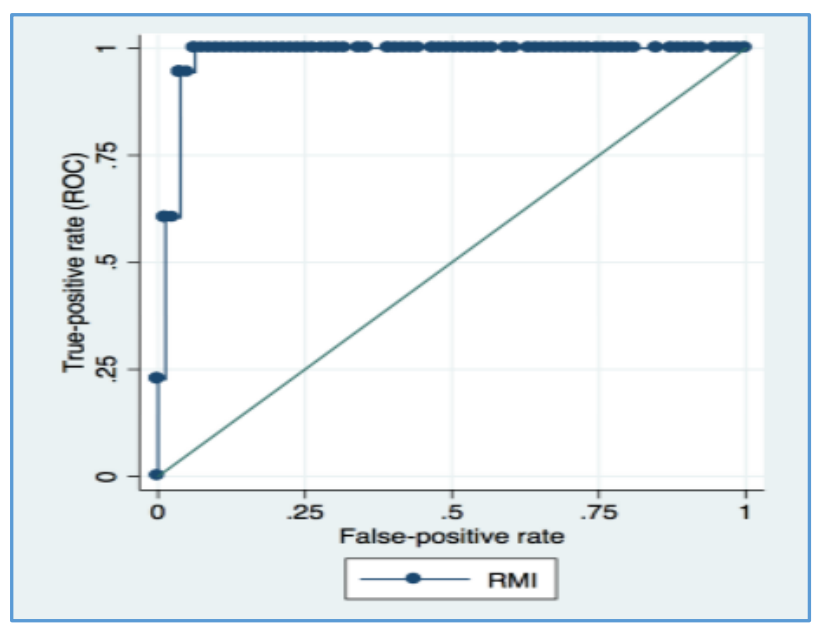

Figure 1. Receiver Operating Characteristics (ROC) Curve of RMI- 4 in differentiating Benign and Malignant Adnexal Masses

\begin{tabular}{|c|c|c|c|c|c|}
\hline Variable & $\begin{array}{c}\text { Sensitivity } \\
(\%)\end{array}$ & $\begin{array}{c}\text { Specificity } \\
(\%)\end{array}$ & $\begin{array}{c}\text { PPV } \\
\text { (\%) }\end{array}$ & $\begin{array}{c}\text { NPV } \\
\text { (\%) }\end{array}$ & AUC \\
\hline \multicolumn{6}{|c|}{ CA125 U/ml } \\
\hline 10 & 46.1 & 100 & 100 & 21.5 & 0.73 \\
\hline 35 & 80.3 & 94.4 & 92.5 & 84.0 & 0.87 \\
\hline 50 & 87.3 & 93.5 & 90.6 & 91.1 & 0.90 \\
\hline 150 & 91.1 & 86.2 & 77.4 & 94.9 & 0.89 \\
\hline USG Score & 88.1 & 98.6 & 98.1 & 91.1 & 0.93 \\
\hline $\begin{array}{c}\text { Menopausal } \\
\text { Status }\end{array}$ & 72.7 & 83.1 & 75.5 & 81.0 & 0.78 \\
\hline Tumour Size & 56.5 & 77.8 & 73.6 & 62.0 & 0.67 \\
\hline RMI -4 & 96.10 & 94.55 & 96.10 & 94.55 & 0.95 \\
\hline
\end{tabular}

Table 8. Sensitivity, Specificity, Positive Predictive Value (PPV), Negative Predictive Value (NPV) of Serum CA 125 Ultrasound Score, Menopausal Status, Tumour Size and RMI- 4 in Diagnosis of an Adnexal Mass

The performance of Serum CA - 125 values at various cut off levels are shown in this table. With a cut off value of 50 $\mathrm{U} / \mathrm{ml}$ in Serum CA - 125 it predicted maximum sensitivity and specificity of $87.3 \%$ and $93.5 \%$ respectively. In one of the variable tumour size it indicated very less diagnostic value for discriminating the ovarian tumour as compared to other parameters with area under curve of 0.67 . RMI -4 which is a combination of all parameters predicted highest diagnosis in maximum number of cases with a area under curve 0.95 .

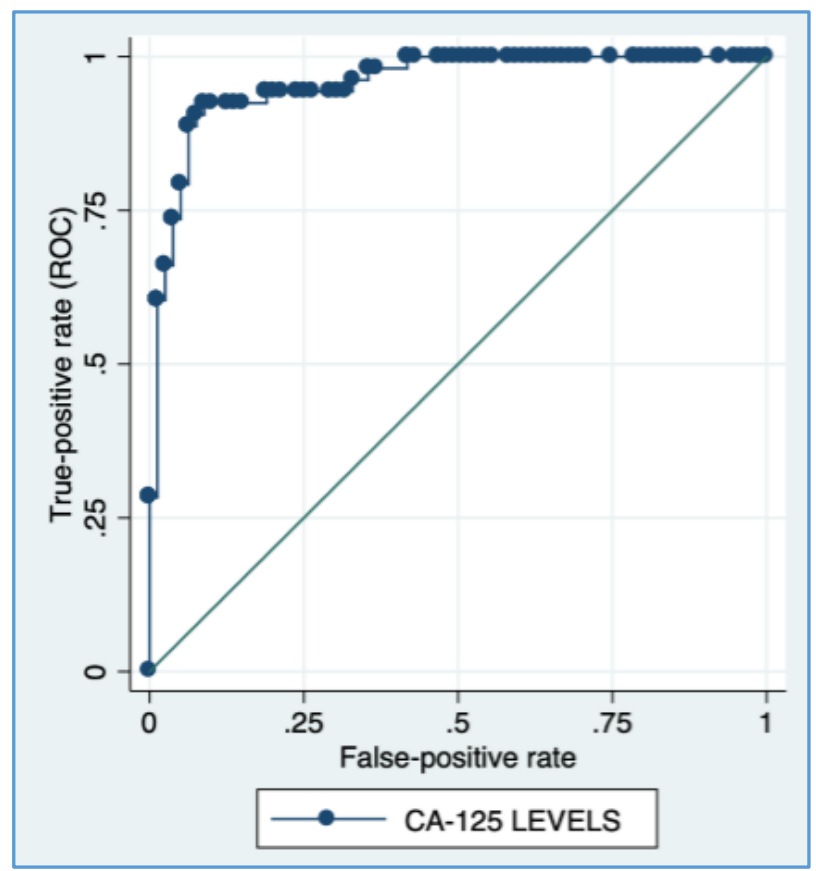

Figure 2. ROC Curve for Sr CA-125 Levels in discriminating between Benign and Malignant Adnexal Masses

\begin{tabular}{|c|c|c|c|c|}
\hline \multirow{2}{*}{ Parameters } & \multirow{2}{*}{$\mathbf{Z}$} & \multirow{2}{*}{ p-Value } & \multicolumn{2}{|c|}{$95 \%$ CI } \\
\hline & & & Lower & Upper \\
\hline Age & 1.70 & $0.089, \mathrm{NS}$ & 0.98 & 1.22 \\
\hline Tumour Size & 1.78 & $0.075, \mathrm{NS}$ & 0.97 & 1.53 \\
\hline USG Score & 4.40 & $0.0001, \mathrm{~S}$ & 2.82 & 15.01 \\
\hline CA 125 Levels & 0.95 & $0.344, \mathrm{NS}$ & 0.99 & 1.00 \\
\hline $\begin{array}{l}\text { Menopausal } \\
\text { Status }\end{array}$ & 0.50 & $0.614, \mathrm{NS}$ & 0.28 & 2.08 \\
\hline
\end{tabular}

On analytical study of CA-125, Ultrasound Score, Menopausal Status, Tumour Size with Histopathological diagnosis as a gold standard. After performing the logistics regression analysis it was found that the best disparity of ovarian malignancy from benign lesion was diagnosed by Ultrasound Score as a salient feature.

\section{DISCUSSION}

The current study has established the helpfulness of RMI in assessment of women with adnexal masses. In our study mean age of benign group is $38.54 \pm 11.31$ and similarly mean age in malignant cases is $52.70 \pm 13.07$. This conclusion coincides with study of Monirath Hav et al and Yamamoto et al who has revealed mean age in benign as $37.0 \pm 8.79$, $39.8 \pm 15.2$ and mean age in malignant group as $50.8 \pm 12.9$, $54.0 \pm 17.5$ respectively.[9],[14] The chances of ovarian malignancy increases in proportionate with the increasing age.[16]

In the present study $76.36 \%$ were diagnosed with malignancy in postmenopausal group and $16.88 \%$ of the same group were with benign tumours. The Menopausal Status of our study gave a sensitivity of $72.7 \%$ and specificity 
of $83.1 \%$ for diagnosing malignant cases. A recent study by Singhal $\mathrm{S}$ et al findings were $40 \%$ sensitivity and $84.3 \%$ specificity for menopausal status. Another study by Aliya et al had a sensitivity of $51.3 \%$ and specificity of $85.6 \%$. Thus in our study as shown is table No. 3 menopausal status is highly predictive for malignancy ( $\mathrm{p}-0.0001$ ) with Odds ratio $15.91(95 \% \mathrm{CI}=6.71-37.66)$. In our study it is depicted that the age range is $41-61$ years for occurrence of malignancy. For women presenting with adnexal mass above 40 years should raise suspicion of malignancy.

In the present study out of 132 patients 77 (58.33\%) were diagnosed as benign and 55 (41.66\%) women were diagnosed as malignant. In present study one of the variable for determining RMI index is tumour size. Tumour size of $\geq 7$ $\mathrm{cms}$ is seen in $81.82 \%$ cases which turned out to be malignant group and $40.26 \%$ came under benign group (p value 0.0001 ). Ovarian size at USG study varied from $3-27 \mathrm{~cm}$. In our study group of patients with malignancy, 45 are having tumour size $>7 \mathrm{~cm}$. This shows the association between the tumour size and malignancy were statistically significant at a $\mathrm{p}$ value of 0.0001 with Odds ratio 6.67 (95\% CI $=2.93$ 15.21). Our findings matching with Sunita Singhal et al (2018), with the result of $70 \%$ in malignant group $48.1 \%$ in benign group had a tumour size $\geq 7 \mathrm{cms}$ with $\mathrm{p}$ value of 0.01 (S). In her study the tumour size of $>7 \mathrm{~cm}$ showing a sensitivity of $70 \%$ and specificity of $51.88 \%$ but in our study the findings of sensitivity and specificity are different was $56.5 \%$ and specificity of $77.8 \%$. According to our findings with tumour size more than $\geq 7 \mathrm{cms}$ the risk of malignancy increases by 1.5 fold. As per logistic regression tumour size alone will not be able to predict malignancy in adnexal masses.

Serum CA- 125 level is universally used a tumour marker for diagnosing ovarian cancer. Simsek et al reported a sensitivity of $78.6 \%$ and specificity of $63.5 \%$ for CA- $125>35$ $\mathrm{U} / \mathrm{ml} .{ }^{[17]}$ In our findings CA- 125 level was significantly higher in malignant group $(1073.17 \pm 1403.67)$ as compared to benign $(39.52 \pm 133.17)$. Among the patients with CA125 levels $>35 \mathrm{U} / \mathrm{ml}, 51(92.73 \%)$ had malignancy and 10 $(12.99 \%)$ benign tumour with a p value 0.0001 . Sixty seven patients (87.01\%) with CA125 levels less than $35 \mathrm{U} / \mathrm{ml}$ had benign lesions, while $4(7.27 \%)$ had malignant disease. In the present study the area under the curve for CA- 125 was 0.87 ( $\geq 35 \mathrm{U} / \mathrm{ml}$ ) and 0.90 (Serum CA125 - >50 U/ml). Our findings are similar to the study accomplished by B.R.Obeidat et al i.e area under curve of $0.80 .{ }^{[18]}$ In the current study Serum CA- 125 with a cut off value of 35 gave a sensitivity of $80.3 \%$ and specificity of $94.4 \%$. The study done by Aliya et al, the value of CA- $125>35$ gave a sensitivity of $70.2 \%$ and $67.6 \%$ specificity. ${ }^{[19]}$ Recent study by 2018 Singhal S et al gave a sensitivity of $75 \%$ and specificity of $90 \%$ for CA- 125 levels $>35 \mathrm{U} / \mathrm{ml} .{ }^{[20]}$ The best cut off value of CA- 125 was 50 $\mathrm{U} / \mathrm{ml}$ with a sensitivity of $87.3 \%$ and specificity of $93.5 \%$ in our study.[3]

Analysis of 132 patients with ultrasound features in respect of benign and malignant patients are as follows. The lesions were multilocular in $64(83.11 \%)$ benign cases and $52(94.54 \%)$ malignant group with a p value 0.047 . Findings as solid area are seen in $52(94.54 \%)$ of malignant cases and $30(38.96 \%)$ in benign group with a p value 0.0001 . The investigations further revealed that out of 132 patients of the study 17 cases had bilateral cyst and 115 had unilocular cyst with a p value 0.039. Similarly rest of the features like metastasis $37(67.27 \%)$ and ascites $36(65.45 \%)$ were predominantly seen in malignant group. Interestingly our findings correlate with the findings of Kestane I et al.[21]

After allotting the score in our study 73 cases have score 1 , while lesions of 59 cases have score 4 (Table no. 8). Out of the $73(95.31 \%)$ patients with an ultrasound score 1, 72 (93.5\%) has benign disease and only 1 (1.81\%) has malignancy with $\mathrm{p}$ value 0.0001 . Fifty nine patients in our study has an ultrasound score of 4, among them, 5 (6.49\%) has benign and 54(98.18\%) has malignant disease with a $\mathrm{p}$ value 0.0001 . The sensitivity and specificity of USG score is $88.1 \%$ and $98.6 \%$ respectively. The sensitivity and specificity of ultrasonography is showing high diagnostic accuracy for evaluation of adnexal mass in our study. A research done by Rao et al in 2014 emphasized that sensitivity and specificity of USG score was $90.57 \%$ and $94.48 \%$ respectively.[3] Singhal S et al findings in respect of USG score are $80 \%$ sensitivity and $94.38 \%$ specificity. The receiver operating curve for USG score in our study was 0.93 . [20] Our results were similar to B.R Obeidat et al i.e area under curve 0.73.[18] Evaluation of Logistic regression analysis with histopathological diagnosis as a constant value, the only parameter i.e USG score can individually diagnose and differentiate benign from malignant adnexal masses ( $p$ value - 0.0001).

After analysing and combining all the individual variables (Ultrasound score (U), Menopausal Status (M), Serum CA125 value and Tumour Size (S)) and incorporating them into the formula we calculated the Risk of Malignancy Index (RMI) - 4. Seventy seven patient had an RMI score less than 450, while 55 had score above 450 . Fifty two of the women with RMI $\geq 450$ had malignant disease while 3 had benign lesions. Among patients with RMI less than 450, 74 had benign disease and 3 had malignant lesions. Observing the RMI - 4 cut off level at 450 the Sensitivity of $90.9 \%$, Specificity of 96.1\%, Positive Predictive Value (PPV) of $94.3 \%$ and Negative Predictive Value (NPV) as $93.7 \%$. In our study the best cut off level at 300 showed Sensitivity of $91.2 \%$, Specificity of $98.7 \%$, PPV of $98.1 \%$, NPV of $93.7 \%$. Yamamoto et al originator of RMI - 4 observed with the cut off level of 450 sensitivity, specificity, PPV, NPV were $86.8 \%, 91.0 \%, 63.5 \%$ and $97.5 \%$ respectively.[14] In the study of Jung woo park et al in 2012 with the cut off value of 400 sensitivity was $77.9 \%$, specificity at $85.9 \%$, PPV at $59.1 \%$ and NPV to be $93.7 \% .{ }^{[8]}$ In 2016 Campos et al observed with a RMI -4 cut off of 450 the sensitivity, specificity, PPV, NPV were $86 \%, 91 \%, 63 \%$ and $97.5 \%$ respectively.[16] Aliya B et al in her publication 2015 observed RMI $>250$ having the sensitivity of $54.05 \%$, specificity of $93.4 \%$, PPV of $55.5 \%$ and NPV of $93.06 \% .{ }^{[19]} \mathrm{A}$ study done in June 2018 with RMI - 4 cut off value of 450 had sensitivity, specificity, PPV, NPV as 67\%, 98.7\%, 93.1\%, $92.4 \%$ respectively. In our sudy the Receiver - Operating Characteristics (ROC) of risk of malignancy index was 0.95 . Our study matched with B R Obiedat et al and Campos et al with a area under curve of 0.91 and 0.85 respectively.[16],[18]

In our study the ability of RMI to differentiate adnexal masses preoperatively as benign or malignant is statistically significant as shown by p value 0.0001 with odds ratio 427.6 $(95 \% \mathrm{CI}=82.98-2203)$. The combination of serum CA-125 level, USG morphology of pelvic mass and menopausal status have become the root cause for diagnosis of malignant pelvic masses. In our study the best cut off level at 300 showed 
Sensitivity of $91.2 \%$, Specificity of $98.7 \%$, PPV of $98.1 \%$, NPV of $93.7 \%$. These values are proving to be important and quiet accurate prediction in preoperative assessment of the patients with adnexal masses.

\section{CONCLUSION}

RMI-4 is the most acceptable process for diagnostic decision of patients with adnexal masses. This is a pragmatic methodology for further action of referring patients for specialized surgical recommendations. As robust screening methods for detecting ovarian malignancy is not available, continuous practice of this method will be an imperative component in diagnosing ovarian malignancy. The present study consolidates that RMI was better diagnostic tool for triaging the adnexal masses, with high risk of malignancy and subsequently guiding the patients to gynaecological oncology centers for suitable and effective surgical interventions.

\section{REFERENCES}

[1] Devi KU. Current status of gynecological cancer care in India. Journal of Gynecologic Oncology 2009;20(2):7780.

[2] Shintre SA, Survase RM, Patil NA, Sayyed RL. Effectiveness of risk of malignancy index to differentiate benign from malignant ovarian masses-a cross sectional study. Int J of Health Sci \& Res 2017;7(5):52-9.

[3] Rao JH. Risk of malignancy index in assessment of pelvic mass. International Journal of Biomedical Research 2014;5(3):184-6.

[4] Irshad F, Irshad M, Naz M, et al. Accuracy of risk of malignancy index. In the preoperative diagnosis of Zovarian malignancy in postmenopausal women. Rawal Medical Journal 2013;38(3):266-70.

[5] Park JW. Four risk of malignancy indices in evaluation of pelvic masses. Journal of Minimally Invasive Gynecology 2014;21(6):S192.

[6] Torres JC, Derchain SF, Faúndes A, et al. Risk-ofmalignancy index in preoperative evaluation of clinically restricted ovarian cancer. Sao Paulo Medical Journal 2002;120(3):72-6.

[7] Cohen JG, White M, Cruz A, et al. In 2014, Can we do better than CA125 in the early detection of ovarian cancer? World Journal of Biological Chemistry 2014;5(3):286-300

[8] Park JW, Park JH, Song ES, et al. Four risk of malignancy indices in evaluation of pelvic masses. Korean Journal of Obstetrics \& Gynecology 2012;55(9):636-43.

[9] Ashrafgangooei T, Rezaeezadeh M. Risk of malignancy index in preoperative evaluation of pelvic masses. Asian Pac J Cancer Prev 2011;12(07):1727-30.
[10] Moolthiya W, Yuenyao P. The risk of malignancy index (RMI) in diagnosis of ovarian malignancy. Asian Pac J Cancer Prev 2009;10(5):865-8.

[11] Tingulstad S, Hagen B, Skjeldestad FE, et al. Evaluation of a risk of malignancy index based on serum CA125, ultrasound findings and menopausal status in the pre-operative diagnosis of pelvic masses. BJOG: An International Journal of Obstetrics \& Gynaecology 1996;103(8):826-31.

[12] Jacobs I, Oram D, Fairbanks J, et al. A risk of malignancy index incorporating CA 125, ultrasound and menopausal status for the accurate preoperative diagnosis of ovarian cancer. BJOG: An International Journal of Obstetrics \& Gynaecology 1990;97(10):9229.

[13] Tingulstad S, Hagen B, Skjeldestad FE, et al. The riskof-malignancy index to evaluate potential ovarian cancers in local hospitals. Obstetrics \& Gynecology 1999;93(3):448-52.

[14] Yamamoto Y, Yamada R, Oguri H, et al. Comparison of four malignancy risk indices in the preoperative evaluation of patients with pelvic masses. European Journal of Obstetrics \& Gynecology and Reproductive Biology 2009;144(2):163-7.

[15] Mohammed ABF, Ahuga VK, Taha M. Validation of the risk of malignancy index in primary evaluation of ovarian masses. Middle East Fertility Society Journal 2014;19(4):324-8.

[16] Campos C, Sarian LO, Jales RM, et al. Performance of the risk of malignancy index for discriminating malignant tumours in women with adnexal masses. Journal of Ultrasound in Medicine 2016;35(1):143-52.

[17] Simsek HS, Tokmak A, Ozgu E, et al. Role of a risk of malignancy index in clinical approaches to adnexal masses. Asian Pac J Cancer Prev 2014;15(18):7793-7.

[18] Obeidat BR, Amarin ZO, Latimer JA, et al. Risk of malignancy index in the preoperative evaluation of pelvic masses. International Journal of Gynecology \& Obstetrics 2004;85(3):255-8.

[19] Aziz AB, Najmi N. Is risk malignancy index a useful tool for predicting malignant ovarian masses in developing countries? Article Id 951256, Obstetrics and Gynecology International 2015;(2015): p. 5.

[20] Singhal S, Rajoria L, Mital P, et al. Risk of malignancy index 4 in preoperative evaluation of patients with ovarian tumours. International Journal of Reproduction, Contraception, Obstetrics and Gynecology 2018;7(6):2467-71.

[21] Kestane I, Senol T, Kahramanoglu I, et al. The use of risk of malignancy index for adnexal masses. Gynecol Obstet (Sunnyvale) 2014;4(226):2161-0932. 